\title{
PIBID/UFPEL: intervenção interdisciplinar numa escola de ensino fundamental
}

\author{
PIBID / UFPEL interdisciplinary activities in elementary school \\ PIBID/UFPEL: una intervención interdisciplinaria en la escuela primaria
}

\author{
Juliana Boanova Souza ${ }^{1}$ \\ Juliana Aparecida Fernando ${ }^{2}$ \\ Maristani Polidori Zamperetti ${ }^{3}$ \\ Denise Castanha de Avila de Lemos ${ }^{4}$
}

\begin{abstract}
Resumo
O Programa Institucional de Bolsa de Iniciação à Docência da Universidade Federal de Pelotas (PIBID/UFPEL) destaca-se por contemplar diferentes áreas das licenciaturas que, em grupos, atuam nas escolas da rede pública de Pelotas/RS promovendo atividades de ensino e aprendizagem interdisciplinares. Nesse contexto, o grupo interdisciplinar de uma escola de ensino fundamental da cidade de Pelotas elaborou o projeto "Corpo em Movimento - Esporte, Linguagem, Espaço e Saúde". A proposta surgiu a partir do diagnóstico escolar realizado pelos acadêmicos pibidianos revelando situações de bullying, agressividade verbal e desrespeito entre os estudantes. Dessa forma, oficinas integrando as diferentes licenciaturas foram elaboradas a fim de promover o respeito, a cooperação e convivência harmoniosa entre os membros da comunidade escolar. O trabalho em um grupo diverso permitiu a integração e colaboração entre as áreas e, principalmente mostrou aos pibidianos a realidade escolar, conhecimento essencial para a formação docente.
\end{abstract}

Palavras-Chave: Aprendizagem, Docência, Interdisciplinaridade, Respeito.

\section{Resumen}

El Programa Institucional de Iniciación de subvención para la enseñanza de la Universidad Federal de Pelotas (PIBID/UFPEL) se destaca por la contemplación de las diferentes áreas de la educación universitaria, en grupos, que trabajan en las escuelas públicas de Pelotas / RS que promuevan la enseñanza y el aprendizaje interdisciplinarios. En este contexto, el grupo interdisciplinario de una escuela primaria en la ciudad de Pelotas preparó el proyecto "Cuerpo en Movimiento - Deporte, Idiomas, Espacio y Salud". La propuesta surgió a partir del diagnóstico realizado por la escuela pibidianos situaciones de acoso que revelan académicas, agresión verbal y la falta de respeto entre los estudiantes. Por lo tanto, la integración de los talleres de diferentes grados se prepararon con el fin de promover el respeto, la cooperación y la coexistencia armoniosa entre los miembros de

\footnotetext{
${ }^{1}$ Acadêmica do Curso de Matemática - Licenciatura, Bolsista do PIBID/UFPEL, Universidade Federal de Pelotas; UFPel, Pelotas, Rio Grande do Sul, Brasil. ju.boanova@bol.com.br

${ }^{2}$ Doutora em Biologia Vegetal, Universidade Federal de Pelotas; UFPel, Pelotas, Rio Grande do Sul, Brasil. juli_fernando@yahoo.com.br
}

3 Doutora em Educação, Universidade Federal de Pelotas; UFPel; Pelotas, Rio Grande do Sul, Brasil. maristaniz@hotmail.com

\footnotetext{
${ }^{4}$ Acadêmica do Curso de Artes Visuais - Licenciatura, Bolsista do PIBID/UFPEL, Universidade Federal de Pelotas; UFPel, Pelotas, Rio Grande do Sul, Brasil. denlemos@gmail.com
} 

e-ISSN 2016/Atual: 2525-7870 | e-ISSN 2015/2016: 2447-018X

la comunidad escolar. Trabajar en un grupo diverso permitido la integración y la colaboración entre las áreas y sobre todo mostró la realidad escolar pibidianos, el conocimiento esencial para la formación del profesorado.

Palabras clave: Aprendizaje, Enseñanza, Interdisciplinariedad, Respeto

\begin{abstract}
The Institutional Program Initiation Scholarships to Teaching of Federal University of Pelotas (PIBID/UFPEL) stands out for contemplating different areas of undergraduate education, in groups, working in schools Pelotas public / RS promoting teaching and interdisciplinary learning. In this context, the interdisciplinary group of a primary school in the city of Pelotas prepared the project "Body in Motion - Sport, Language, Space and Health". The proposal arises from the school diagnosis made by academics showing bullying situations, verbal aggression and disrespect among students. Thus, workshops integrating the different degrees were prepared in order to promote respect, cooperation and harmonious coexistence among members of the school community. Working in a diverse group enabled the integration and collaboration between the areas and mainly showed the school reality, essential knowledge for teacher training.
\end{abstract}

Keywords: Learning, Teaching, Interdisciplinarity, Respect.

\title{
1. Introdução
}

O Programa Institucional de Bolsas de Iniciação à Docência (PIBID) é elaborado e financiado pela Coordenadoria de Aperfeiçoamento de Pessoal de Nível Superior - CAPES promovendo a integração entre educação superior e educação básica a fim de associar conceitos teóricos às atividades práticas, aspectos fundamentais à formação docentes. Para o sucesso desta parceria é importante investigar a realidade das escolas públicas para posterior planejamento das ações. Nesse contexto, um grupo de acadêmicos pibidianos da Universidade Federal de Pelotas (UFPEL) das áreas de Matemática, Artes Visuais, Biologia, Letras, Educação Física, Geografia e História reuniram-se durante os anos de 2014/2015, semanalmente, numa escola de ensino fundamental da rede pública de Pelotas e organizaram o diagnóstico escolar a partir de entrevistas com estudantes, professores, direção, caracterização da estrutura física, estudos do projeto pedagógico e análise do contexto histórico e social da escola.

O diagnóstico detectou a constante presença de bullying, agressividade, desrespeito mútuo, e um grande desejo dos alunos de possuírem um espaço adequado para a realização de atividades esportivas. Dessa forma, o trabalho interdisciplinar do grupo de pibidianos propôs a retomada de atitudes de respeito, autonomia, cooperação e tolerância através do tema "Corpo em Movimento - Esporte, Linguagem, Espaço e Saúde" resgatando o respeito às diferenças, ao outro e a si mesmo enfatizando aspectos da alimentação saudável e desenvolvimento da prática esportiva, uma demanda evidenciada pelos estudantes. Cabe evidenciar que o enfoque interdisciplinar do projeto permitiu a vivência docente aos pibidianos, assim como o conhecimento de outras áreas. As atividades interdisciplinares 
promovem a articulação das ações pedagógicas e incentivam o trabalho colaborativo entre os participantes (SALGADO; SILVA, 2013).

\section{Metodologia}

Considerando o caráter diverso do grupo de trabalho o projeto foi subdividido em quatro momentos e aplicado às turmas do sexto, oitavo e nono anos. Cabe evidenciar que um pequeno caderno foi distribuído no início da aplicação do projeto e os alunos foram incentivados a anotar suas impressões ao final de cada atividade. Essa prática é referida como Mini Diário.

\subsection{Momento I: Café Consciência}

A atividade física é importante para a natureza humana e permite uma vida prazerosa, proporcionando momentos de diversão e companheirismo entre as pessoas. Além da atividade física, um dos pontos mais importantes para a saúde é a alimentação. A alimentação saudável envolve a escolha de alimentos não somente para manter o peso ideal, mas também para garantir uma saúde plena, fornecendo os nutrientes e vitaminas necessárias para o dia a dia.

A classificação dos nutrientes em construtores (proteínas, água), energéticos (carboidratos, lipídios) e reguladores ou protetores (fibras, vitaminas, minerais, água), juntamente com a pirâmide alimentar são necessários para a melhor compreensão da alimentação e necessidades do organismo (TOMASI; SPAZZIANI, 2008), evidenciando que o tema alimentação saudável se enquadra no eixo temático Ser Humano e Saúde nos Parâmetros Curriculares Nacionais - PCNs (BRASIL, 1998). A abordagem desta temática nos anos finais do ensino fundamental é essencial para acompanhar o desenvolvimento físico (altura, peso, musculatura) e para o estudo dos elementos que compõem a dieta básica, exemplos estes que também podem servir de contexto para a aprendizagem de outros conteúdos como os matemáticos.

A presente atividade teve início com indagações verdadeiras e outras falsas sobre alimentação: Mascar chiclete faz mal ao estômago?; Comer sempre os mesmos alimentos, sem variar o cardápio, pode trazer algum dano à saúde? É verdade que a laranja auxilia a digestão de uma refeição pesada, como a feijoada?; É verdade que tomar qualquer tipo de bebida durante as refeições não é bom?; Comer banana reduz cãibra?; Ficar sem comer emagrece?; É verdade que não se deve deitar logo após uma refeição?; É melhor comer frutas com ou sem casca?; Praticar atividade física em jejum emagrece? 

e-ISSN 2016/Atual: 2525-7870 | e-ISSN 2015/2016: 2447-018X

Em seguida, os alunos manifestaram suas opiniões e questionamentos aos acadêmicos pibidianos que, com a projeção de ilustrações, iniciaram discussão a respeito do tema alimentação saudável. Após isso, foi feita uma apresentação de slides com breve introdução dos grupos de nutrientes construtores, energéticos e reguladores. A oficina teve continuidade com a degustação de alguns alimentos enfatizando e retomando aspectos alimentares como a importância de vitaminas e demais nutrientes.

A educação nutricional se constitui numa "variedade de experiências planejadas para facilitar a adoção voluntária de hábitos alimentares ou de qualquer comportamento relacionado à alimentação que conduza à saúde e ao bem estar" (FAGIOLI; NASSER, 2006, p. 52).

\section{Atividade}

Os alunos foram divididos em três grupos: cada integrante recebeu um envelope com o nome de determinado alimento: pão, chocolate, espinafre, brócolis, laranja, cenoura, batata, feijão, banana, carne, arroz, espinafre, maçã, macarrão, pipoca, leite, cereal, bolacha. Ao abrirem os envelopes os alunos relacionaram o alimento com a tabela de nutrientes (preparada em cartolina) e colando com fita adesiva no local que "acreditavam" adequado - alimentos energéticos: pão, chocolate, batata, arroz, macarrão e bolacha; alimentos construtores: feijão, ovo, leite, espinafre, brócolis e carne', alimentos reguladores: laranja, cenoura, banana, maça, cereal e pipoca (Figura 1).

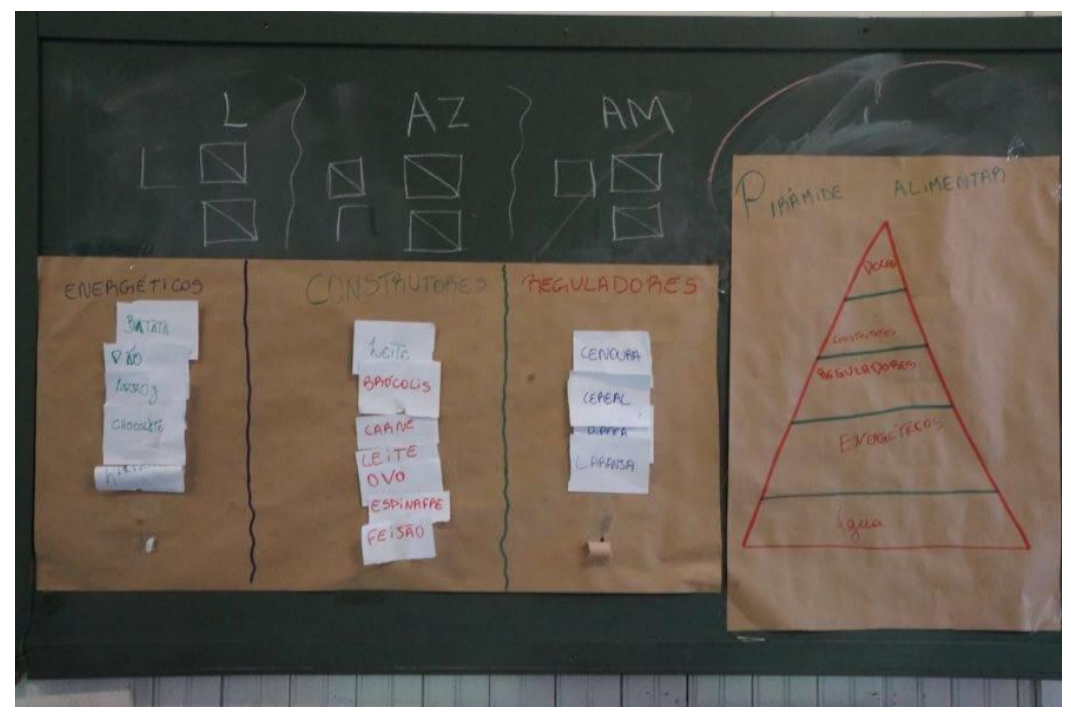

Figura 1: Atividade Feita com os estudantes.

Fonte: Dos autores (2016) 


\subsection{Momento II: Bola}

Os conceitos geométricos constituem parte importante do currículo de Matemática no ensino fundamental, pois permite que o aluno compreenda, descreva e represente, de forma organizada, o mundo em que vive. Nesse contexto, a Geometria é um tema pelo qual os alunos costumam se interessar naturalmente. As noções geométricas contribuem para a aprendizagem de números e medidas, estimulando o aluno a observar, perceber semelhanças e diferenças, identificar regularidades (ZAMPA; VIEIRA, 2011).

Estudar com espaço e forma pressupõe que o professor de Matemática explore situações em que sejam necessárias algumas construções geométricas com régua e compasso, como visualização e aplicação de propriedades das figuras, além da construção de outras relações. Este bloco de conteúdos contempla não apenas o estudo das formas, mas também as noções relativas à posição, localização de figuras e deslocamentos no plano e sistemas de coordenadas.

Para Vigotski (2001), a aprendizagem tem um papel fundamental no processo de desenvolvimento humano, pois é por meio dela que as pessoas internalizam sua cultura enfatizando que a escola é o local principal no qual essa internalização ocorre sendo a ação pedagógica e a intervenção do professor aspectos importantes na constituição do processo de ensino.

Nesse contexto, a intervenção junto aos alunos iniciou-se com projeção de imagens de diferentes tipos de bolas (suíça, tênis, gude, basquete, vôlei...) e questionamentos como: "Com que figura geométrica essas bolas se assemelham"? E com que sólido geométrico? E o Sol o que é? E o mundo, qual sua forma? Após essa integração os alunos concluem que a realidade diária constitui-se de diversas esferas (Sol, planeta Terra). Em seguida, uniu-se a geometria plana com a geometria espacial, em que os estudantes manusearam bambolês (forma de círculo - geometria plana) e, em grupos, uniram vários bambolês, encaixando um dentro do outro e formando uma esfera (geometria espacial).

A atividade seguinte consistiu em abordar o Sistema Solar mostrando que o conjunto de objetos astronômicos se liga ao Sol através da gravidade e se formaram por meio do colapso de uma nuvem molecular gigante há 4,6 bilhões de anos atrás. Entre os muitos corpos que orbitam ao redor do Sol, a maior parte da massa está contida dentro de oito planetas (Mercúrio, Vênus, Terra, Marte, Júpiter, Saturno, Urano e Netuno) relativamente solitários, cujas órbitas são quase circulares e se encontram dentro de um disco quase plano. 

e-ISSN 2016/Atual: 2525-7870 | e-ISSN 2015/2016: 2447-018X

Também foi realizada a atividade "Corpo Hemisferizado" onde, inicialmente trabalhou-se com as crianças os seus hemisférios corporais. Com o auxílio de dois metros de cordão (barbante), esses alunos representaram o Equador Corporal em seus corpos, considerando-se como o Planeta Terra e passando um cordão à volta da cintura. A seguir, perguntou-se aos alunos "o quê o cordão estabeleceu”. É importante já ter trabalhado as noções de "acima" e "embaixo" com o auxílio de objetos e de uma mesa. Com o uso do globo terrestre, mostrou-se que a Terra está "solta" no espaço e, portanto, não existe "acima de" e "embaixo de" quando se trata de representações do planisfério (mapas), pois a Terra não está sobre alguma coisa. Foi fundamental manter presente um globo e fazer a associação: globo/Equador, criação de dois hemisférios terrestres - Norte e Sul, com o corpo/cintura, criação de dois hemisférios corporais.

Empregando mais dois metros de cordão, propôs-se que as crianças passassem pelos seus corpos no sentido vertical. A linha "traçada verticalmente" passa na frente, sobre o nariz e o umbigo, e nas costas, sobre o centro da coluna, estabelecendo dois hemisférios, o direito e o esquerdo. Atenção especial foi dada à simetria corporal: o que há duplicidade "um de cada lado", por exemplo, os braços, as orelhas, já o que é apenas unidade está no "centro", por exemplo, o nariz. O coração está no centro voltado suavemente para a esquerda. No corpo há dois hemisférios, o esquerdo (lado do coração) e o direito (outro lado). Na lateralidade, a criança projeta um dos hemisférios no estabelecimento das relações projetivas.

Para a finalização da atividade e, mais uma vez enfatizar a interdisciplinaridade embutida neste projeto, os acadêmicos pibidianos explanaram sobre a história da bola enfatizando os diferentes esportes que se utilizam deste objeto. Posteriormente, pensando numa aproximação com a forma de criar bolas utilizadas pelos indígenas brasileiros, os quais confeccionam bolas feitas de bexigas de animais, folhas, fibras vegetais e látex, feita de seiva da mangabeira (FERNANDES, 2009), recriou-se a metodologia de confecção de bolas artesanais e, os alunos dividiram-se em pequenos grupos e confeccionaram bolas a partir de balões e fita adesiva e interagiram tanto na construção do objeto quanto nas brincadeiras com as mãos e os pés (Figura 2). 


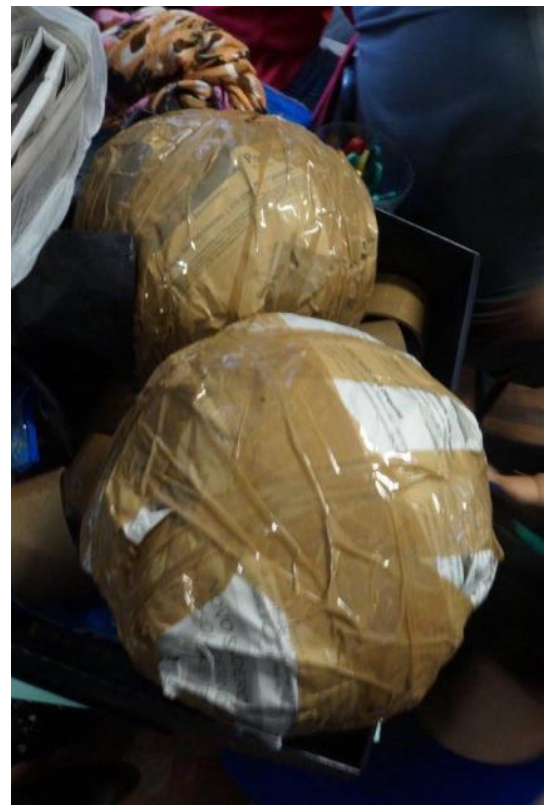

Figura 2: Bolas confeccionadas pelos alunos a partir de balão e jornal.

Fonte: Dos autores (2016)

\subsection{Momento III: Circuito na praça}

A procura por práticas corporais diferenciadas e a necessidade de experimentar sensações diferentes das produzidas pelas práticas convencionais atrai as atenções dos jovens. Estas atividades surgem em diferentes ambientes, como parques e praças. Especificamente, o slackline, por necessitar de um espaço relativamente pequeno para ser montado e, por ser considerado "esporte radical”, é uma prática corporal cada vez mais procurada (Figura 3).

Considerando que a escola enfrentava problemas de infraestrutura, sem espaço para as atividades físicas, optou-se por aplicar um circuito de atividades físicas com bola, corrida e o slackline em ambiente ao ar livre, ou seja, na praça localizada nas proximidades da escola. $\mathrm{O}$ encerramento deu-se com a distribuição de lanche para posterior retorno à escola.

No local de aplicação das atividades, os alunos foram divididos em grupos aleatórios (a turma tem um total de 18 alunos, sendo assim dois grupos com nove alunos cada). Um grupo realizou a atividade de slackline com o auxílio dos aplicadores (pibidianos) durante aproximadamente 30 minutos. O slackline é um esporte de equilíbrio sobre uma fita de nylon, estreita e flexível, praticado geralmente a uma altura de $30 \mathrm{~cm}$ do chão. Originou-se da escalada e é um excelente treino de equilíbrio, o qual vem sendo desenvolvido e difundido em todo o mundo.

O primeiro grupo ficou com alguns pibidianos no slackline e o segundo grupo de alunos desenvolveu a gincana interativa: um aluno partiu do ponto inicial com um bastão na mão até ultrapassar um obstáculo humano (dois colegas da turma); numa pista de skate esse 

e-ISSN 2016/Atual: 2525-7870 | e-ISSN 2015/2016: 2447-018X

aluno subiu e desceu todos os obstáculos de concreto até chegar ao outro colega entregandolhe o bastão e pegando uma bola; o colega com o bastão refez o caminho até o ponto inicial da gincana e o aluno com a bola retornou à pista passando por dois colegas com bambolê; ambos encontraram-se no ponto de partida.

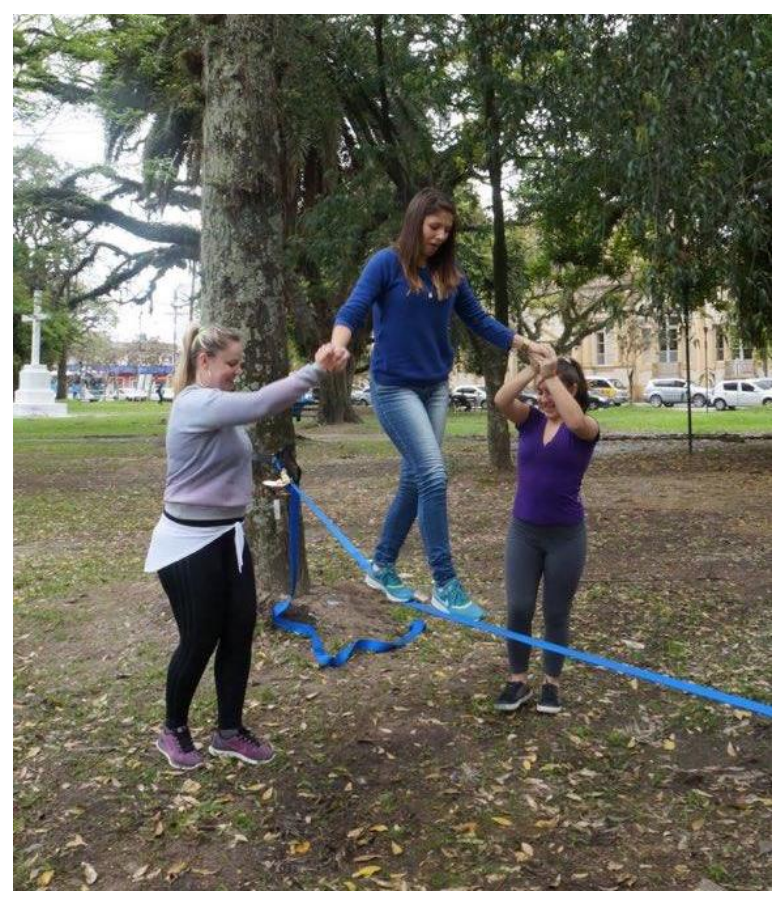

Figura 3: Pibidiana mostrando para os alunos como andar no slackline.

Fonte: Dos autores (2016).

\subsection{Momento IV: Mini Diário}

Ao final de cada dia de aplicação foram recolhidos os Mini Diários, ressaltando que o anonimato poderia ser mantido (Figura 4). Todos os alunos escreveram, desenharam e expressaram suas opiniões. Muitos ressaltaram que gostaram de construir a bola, praticar o slackline e fazer um lanche após as atividades. Este instrumento de pesquisa encontra-se na escola, e tem sido utilizado como registro das atividades no decorrer de 2016. 


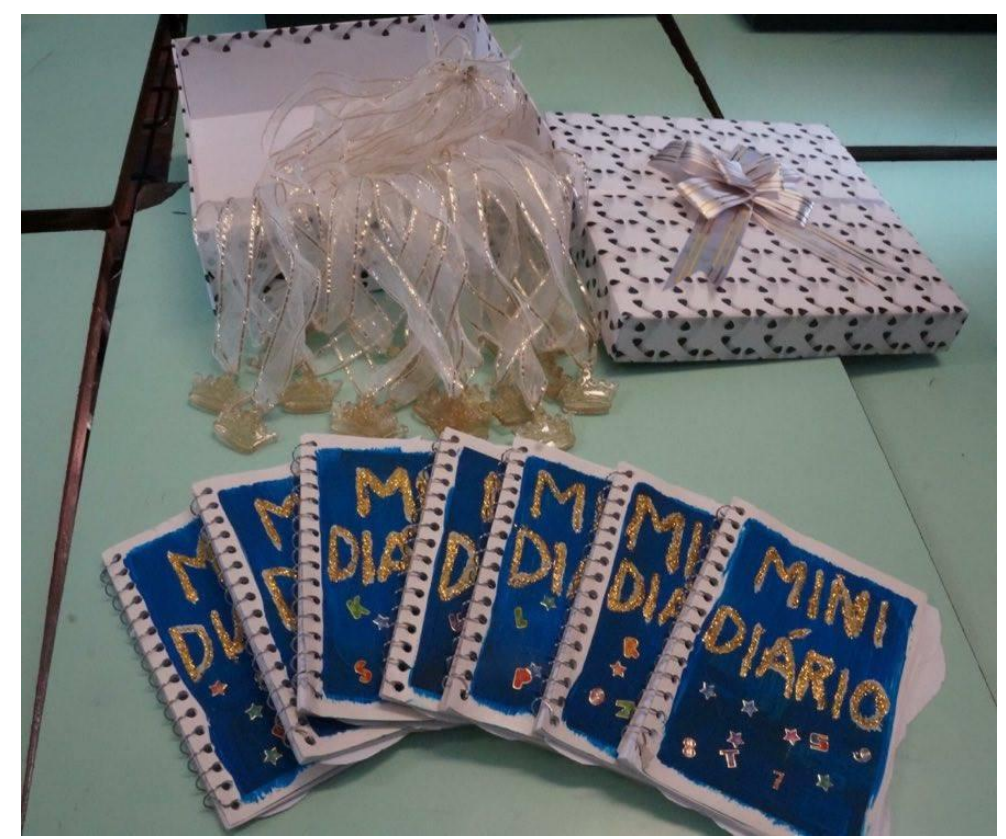

Figura 4: Imagem dos mini diários e das medalhas.

Fonte: Dos autores (2016).

\section{Conclusões}

A experiência interdisciplinar promoveu a troca de ações e pensamentos entre as diferentes áreas tornando a integração entre os acadêmicos pibidianos fator relevante diante de alguns desafios durante a aplicação do projeto. As dificuldades apontadas relacionaram-se com a falta de espaço na escola, tempo chuvoso quando da atividade em ambiente externo (praça), sendo necessário agendamento de dia extra, onde se verificou ser essencial o respeito e consenso na tomada de decisões. A convivência com os professores da escola destacou-se pela troca de informações e conhecimentos ainda não vivenciados pelos acadêmicos, evidenciando que o PIBID permitiu esta interação. A inserção no ambiente escolar mesmo que diante de dificuldades diárias enfrentadas pela escola motivou e incrementou a aprendizagem do futuro docente da educação básica de ensino.

Cabe ressaltar que os alunos foram participativos nas atividades e, pelos relatos nos pequenos cadernos aprovaram as atividades.

O PIBID é um programa de importância para a consolidação de conhecimentos tanto da rede superior de ensino quanto da educação básica. 


\section{Referências bibliográficas}

BRASIL. Ministério da Educação. Secretaria de Ensino Fundamental. Parâmetros curriculares nacionais: apresentação dos temas transversais. Brasília: MEC/SEF, 1998.

FAGIOLI, D.; NASSER, L. A. Educação nutricional na infância e na adolescência: planejamento, intervenção, avaliação e dinâmicas. São Paulo: RCN Editora, 2006, 244p.

FERNANDES, H. J. Etnografia visual das mangabeiras nas matas do tabuleiro costeiro. Dissertação (Mestrado em Antropologia Social) - Universidade Federal do Rio Grande do Norte - Centro de Ciências Humanas, Letras e Artes. Programa de Pós-Graduação em Antropologia Social, 2009.

MOTA, J. O valor da atividade física para uma educação de estilo de vida. In: II Congresso A Escola cultural e os valores. Évora, Portugal, 1992.

SAlGADO, T. D.M.; SILVA, M. T. X. Trabalho interdisciplinar no PIBID da UFRGS: reflexões sobre a caminhada da intenção à realização e os reflexos para a formação dos futuros docentes. In: UBERTI, L.; BELLO, S.E.L. (ORG.). Iniciação à docência: articulações entre ensino e pesquisa. São Leopoldo: Oikos, 2013, p.213-229.

TOMASI, L. C.; SPAZZIANI, M. L. Construindo atitudes para uma vida saudável: uma experiência educativa com alunos do ensino fundamental. Revista Simbio-Logias, v. 1, n. 2, p. 1-15, 2008.

VIGOTSKI, L. S. A Construção do Pensamento e da Linguagem. São Paulo, Martins Fontes, 2001. 496p.

ZAMPA, R.; VIEIRA, C. M. A geometria na Matemática das séries iniciais do ensino fundamental. Revista da Educação Matemática da UFOP, vol 1, 2011. Disponível em: http://www.cead.ufop.br/jornal/index.php/redumat/article/viewFile/326/284 Acesso em: 01 dez. 2015. 